\title{
ERRATUM
}

\section{Comparison of turbulent boundary layers over smooth and rough surfaces up to high Reynolds numbers - ERRATUM}

\author{
D. T. Squire, C. Morrill-Winter, N. Hutchins, M. P. Schultz, J. C. Klewicki \\ and I. Marusic
}

doi:10.1017/jfm.2016.196, Published by Cambridge University Press,

14 April 2016

In the published version of figure 7 errors were unfortunately introduced in the data sets shown. Figure 7 should be replaced by the figure shown below. The publisher apologises to the authors, editors and readers for this error.
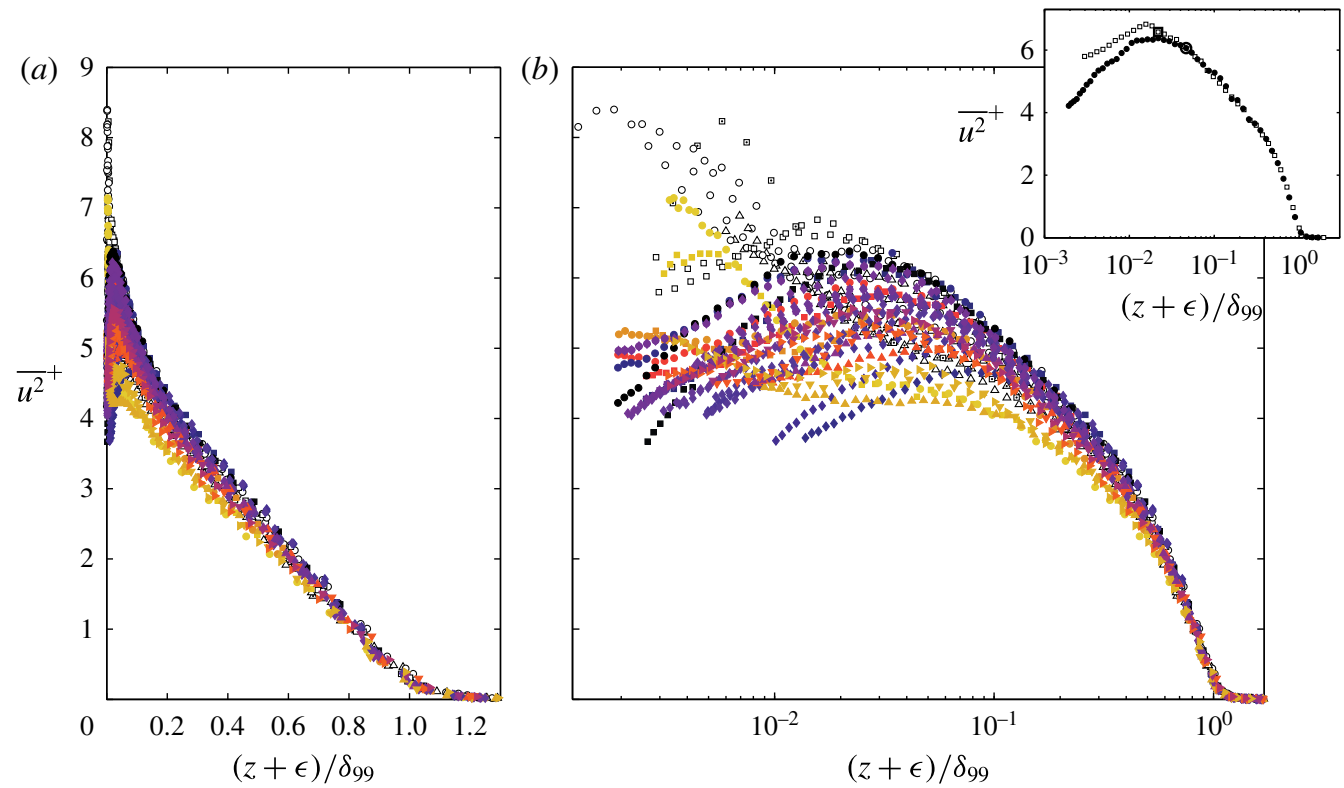

FIgURE 7. (Colour online) The streamwise velocity variance for all smooth- and roughwall data. A linear abscissa is used in $(a)$ and a logarithmic abscissa is used in $(b)$. In the inset of $(b)$, the highest Reynolds number smooth-wall profile $\left(\delta_{99}^{+}=21430\right)$ is compared to the highest Reynolds number rough-wall profile $\left(\delta_{99}^{+}=29900\right)$.

\section{REFERENCE}

Squire, D. T., Morrill-Winter, C., Hutchins, N., Schultz, M. P., Klewicki, J. C. \& MARUSIC, I. 2016 Comparison of turbulent boundary layers over smooth and rough surfaces up to high Reynolds numbers. J. Fluid Mech. 795, 210-240. 